\title{
Declining Country-Level Food Self-Sufficiency Suggests Future Food Insecurities
}

\author{
John R. Schramski ${ }^{1}$. C. Brock Woodson ${ }^{1}$ - Garrett Steck ${ }^{1}$ - Dylan Munn ${ }^{1}$ · James H. Brown ${ }^{2}$
}

Received: 8 March 2019 / Revised: 5 June 2019 / Accepted: 22 June 2019 / Published online: 2 July 2019

(c) The Author(s) 2019, corrected publication 2019

\begin{abstract}
Global food security for a population of 9 billion by 2050 depends on a complex socioeconomic and biophysical system. Current strategies involve decreasing food losses, increasing yields, and improving distribution efficiencies. Herein, we use a systemsbased approach to show that contrary to a historically rising global dietary energy production (DEP: per capita calories grown or captured), food self-sufficiency at the country-level has been in a four-decade decline as the number of countries generating insufficient DEP for their populations continue to increase at a steadfast rate. Global trade and food imports for the most part have kept up and compensated for these growing declines. However, the necessary expansion in food exports and distribution is fueled by ever-increasing growth in non-renewable fossil fuel use resulting in increasing instability in present society.
\end{abstract}

Keywords Food security · Food self-sufficiency $\cdot$ Energy $\cdot$ Dietary energy produced $\cdot$ Urbanization

\section{Introduction}

Food security for an increasing population faced with diminishing natural resources is requiring ever more complex socioeconomic and biophysical evaluations and solutions (Tilman et al. 2011; Godfray et al. 2010; WHO and FIUWA 2017; WFP and FIA 2015; Pimentel and Pimentel 2008; Cole et al. 2018; FAO 2016). While food supply at the table is a traditional food security metric (individual perspective), actual food production will always be a primary metric in the food supply chain. We need to grow the calories before we distribute them. We simplify by focusing on production, which allows us to identify necessary proactive steps to improve food security in an otherwise exceedingly complex food supply chain.

Electronic supplementary material The online version of this article (https://doi.org/10.1007/s41247-019-0060-0) contains supplementary material, which is available to authorized users.

John R. Schramski

jschrams@uga.edu

1 College of Engineering, University of Georgia, Athens, GA 30602, USA

2 Department of Biology, University of New Mexico, Albuquerque, NM 87131, USA
Herein, we show that while global food production continues to increase, average country-level food self-sufficiency has been consistently decreasing for the past half-century and that observable trends like urbanization and increasing population density correlate with these declines. Scale matters; human societal units from families and local communities to the global economy and population are highly organized and powerful self-organizing resource dissipative systems are growing rapidly in size, power, and complexity (Waters et al. 2016; Bettencourt et al. 2007; Rees 2012; Nekola et al. 2013). Correspondingly, to capture these emergent influences, we scale the food self-sufficiency dilemma in terms of per capita food production on a country-bycountry basis. Country-level regulations, such as tax codes, import quotas, incentive schemes, and registration and data collection systems, along with less formalized nationalism tend to result in relatively homogeneous values of human macroecological variables, such as trends in population, GDP, and indices of well-being within national boundaries. Country-level data provide reliable, standardized, quantitative information on socioeconomic factors, such as natural resource extraction, agricultural production, demography, and economic activity and on biophysical factors, such as water availability, arable land, and temperature.

Conservatively and for simplicity, we define food selfsufficiency thermodynamically as the domestic production of sufficient per capita calories. This definition assigns each 
domestic population's per capita calorie needs to their country's farm and ocean production which informs countries whether they are producers (producing more than per capita needs) or consumers (producing less than per capita needs) in the food supply system. Food self-sufficiency therefore does not imply a given country is assigned to specifically feed their own population. Rather it implies that a country's population represents a load on the global food supply system and we are measuring to what degree they are compensating that load with their own calorie production within the same food system. We use dietary energy produced (DEP) to quantify food production, and conservatively assume $2000 \mathrm{kcal}$ per capita per day as a reasonable threshold for basic nutrition (Alexandratos and Bruinsma 2012). DEP is the per capita food calories grown or captured available for consumption by humans (Porkka et al. 2013). Food production from farm and ocean will always be the first step in the food supply chain. The global food system's ability to produce and also distribute additional calories to account for waste, food choice, and macro and micronutrients in addition to simple calorie production is beyond the scope of this paper but otherwise worsens the food self-sufficiency trends we quantify (e.g., thermodynamically humans require sufficient calories, but also need nutrients).

\section{Results}

Here we have analyzed trends in DEP for 164 countries for the 45-year period from 1965 to 2010. From 1965 to 2010, while the number of food calories per capita produced by global agriculture and fisheries increased, the average DEP for the
164 countries analyzed actually decreased (Fig. 1a). These trends reflect increasing variance and disparity in food production among countries when accounting for their population's own needs-while a few produced much more food, most produced less. The number of countries producing enough food to meet the caloric requirements of their populations decreased by $35 \%$, from 101 to 66 , over the 45 -year period (Fig. 1b); on average, curiously persistent, three countries fell into food production deficit every 4 years. These declines are consistent with current food security circumstances (WHO and FIUWA 2017; FAO 2009; Chaudhary et al. 2018), but clarify the self-organizing, resource-consumptive power of human associations at scale. As more countries produce less DEP, remaining countries are thermodynamically required (and for the most part rewarded) to temporarily provide more. Under-producing countries achieve adequate diets by importing more food. The remaining large producers are then required to invest in further high-volume unsustainable practices, and therefore short-term production erodes their own long-term prognosis. The market forces involved in these alignments are well beyond the scope and intention of this paper (Pimentel and Pimentel 2008; Brown et al. 2011, 2013). The inter-country results (Fig. 1) are theoretically expected in a globally traded economic system, constrained by a finite biosphere. As countries unsustainably harvest their habitats to provide for not only their own daily metabolism, they also harvest a wide variety of other material and market needs which further pressures their arable lands (Ehrlich and Harte 2015; Smil 2013; Hall and Day 2009; Schramski et al. 2015).

Observed trends and the resulting dilemma for global food security are due largely to dramatic changes in human ecology and demography with corresponding a

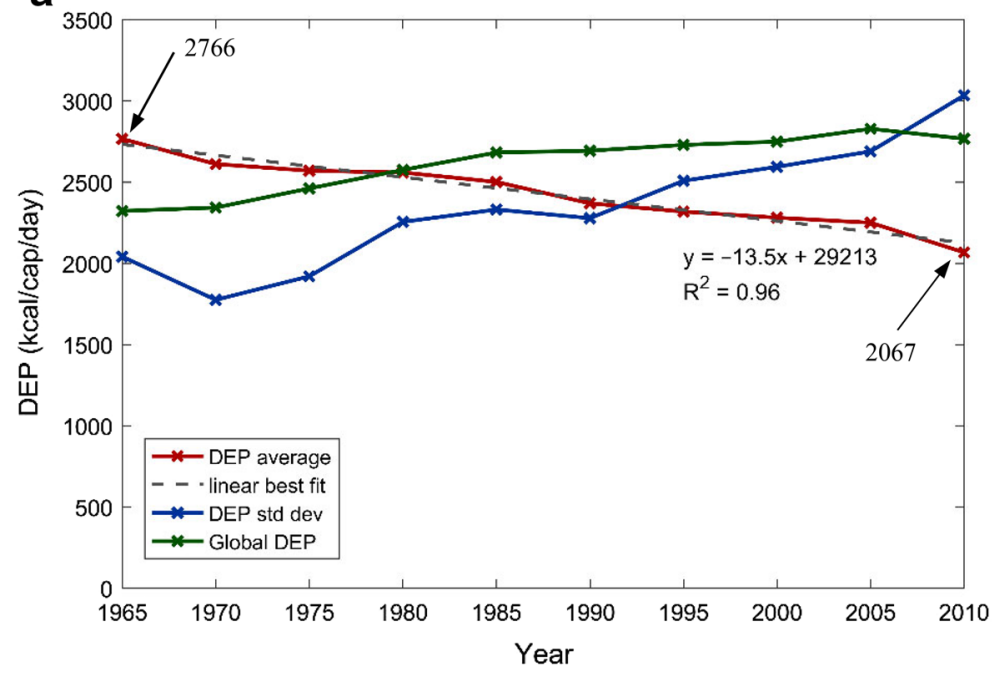

b

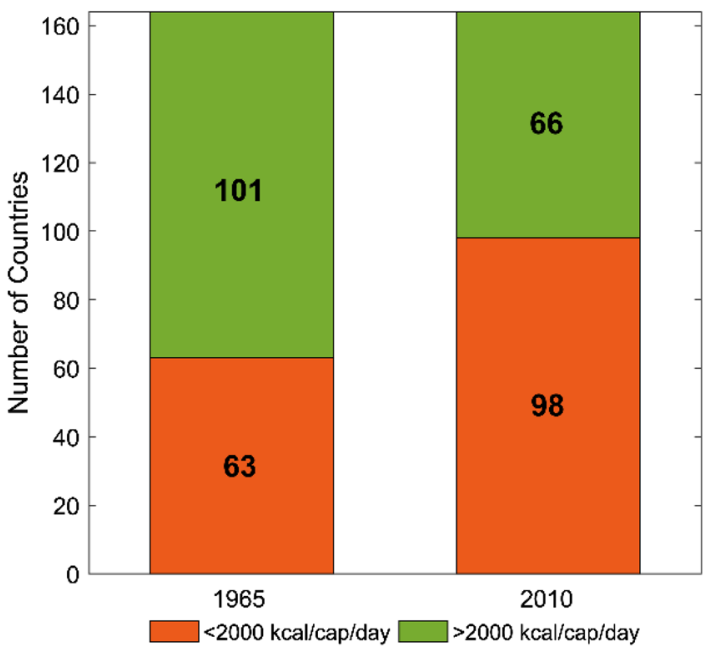

Fig. 1 Change in dietary energy produced (DEP) from 1965 to 2010. a Global DEP, average DEP for 164 countries, and the standard deviation in DEP among the 164 countries. b Number of countries producing more or less than $2000 \mathrm{kcal} / \mathrm{cap} /$ day in 1965 and 2010 (Color figure online) 


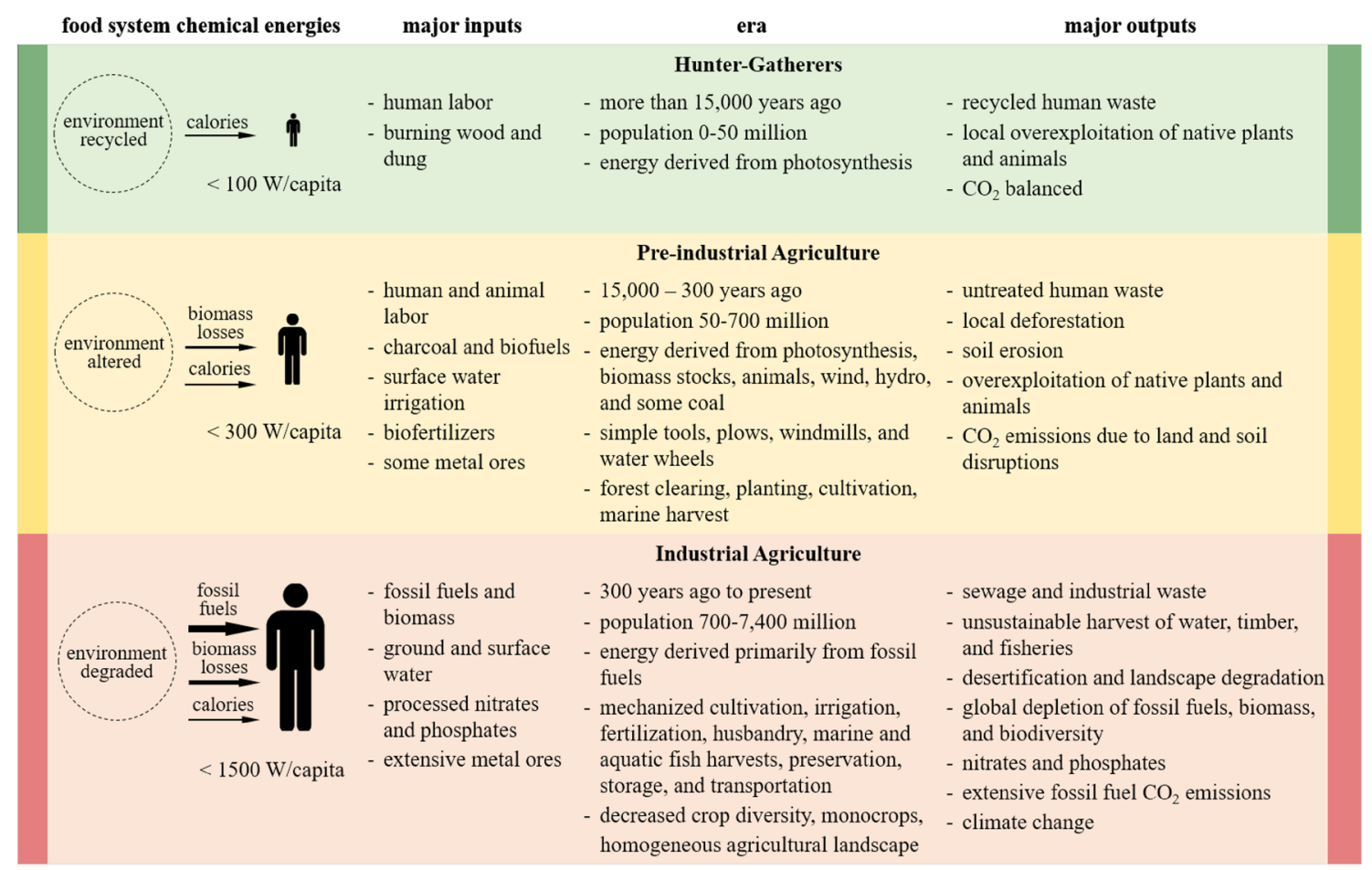

Fig. 2 Consequences of increasing agricultural intensity, urbanization, and technology. Per capita energy consumption (W/capita) increases with agricultural intensification. For additional informa-

detrimental natural resource consequences (Fig. 2). In just 15,000 years, humans have increased from no more than about 50 million subsistence hunter-gatherers living at low densities in approximate balance with earth's ecological processes to agricultural-industrial-technological societies of over 7.5 billion people, mostly crowded into cities. From Jericho, Constantinople, and Rome, to Beijing, London, and Tokyo, cities and their urban ecosystems have become the major habitat of our species. They now hold $>55 \%$ of the global population and represent the new endpoint of ecological succession in the Anthropocene (Rees 2012; Clements 1916; Odum 1969). In just 49 years (1965-2014), urbanization increased from 37 to 54\% and is now increasing at almost $1.0 \%$ per year; the number of cities larger than 300,000 grew from 554 to 1664; the number of cities larger than 10 million increased from 3 to a mind boggling 28 , an almost tenfold increase (Nations 2014). As urbanization continues to spread dramatically, the most serious resource concern is how much longer the global trade pattern of food supply can rely on the countryside to support both the Earth's biological metabolism and civilization's extra-biological resource use (Cumming et al. 2014). Unlike natural climax ecosystems, cities are not in balance with energy flow and other ecological processes; they are hardscapes acting as sinks of energy and sources of pollutants (Rees 2012; Prigogine 1977). Urban tion, the authors suggest Pimentel and Pimentel, 2008 and Smil, 2013 (Pimentel and Pimentel 2008; Smil 2013) (Color figure online)

humans consume far more energy and other resources and produce more industrial wastes than their past huntergatherer ancestors and current rural counterparts. Consequently percent urbanization is now a reasonably accurate predictor of each country's rate of resource consumption (Rees 1999; Burger 2015; Burger et al. 2017).

The ongoing urban demographic shift is correlated to declining food self-sufficiency (Fig. 3a, b). In 1965, most predominantly rural countries with low to intermediate population densities produced enough food for their populations and only two of the most highly urbanized countries (>75\% urban), Bermuda and Malta had large food production deficits ( $\ll 2000 \mathrm{kcal} /$ capita/day). In only 45 years, by 2010 all of the countries with dense, highly urbanized populations had large food production deficits. More clearly, as population density of most countries increased, an accurate indicator of environmental pressure (Pascual and Barbier 2006; Duh et al. 2008; Briggs 1999), DEP declined substantially. For example, in 2010, the average population density of the 98 consumer countries at 168 people $/ \mathrm{km}^{2}$ is more than double the average density of 78 people $/ \mathrm{km}^{2}$ of the 66 remaining producer countries. The ramifications of these correlations weigh heavily on a global population trending urban at $1 \%$ per year. The underlying reasons for the variation and trends in each country's net 45-year trajectory of DEP (Fig. 3c) are complex (e.g., temporal and spatial variation in ecological 


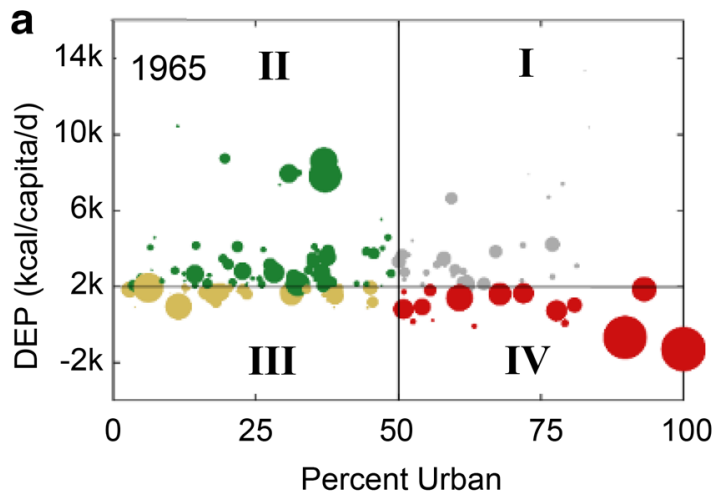

C

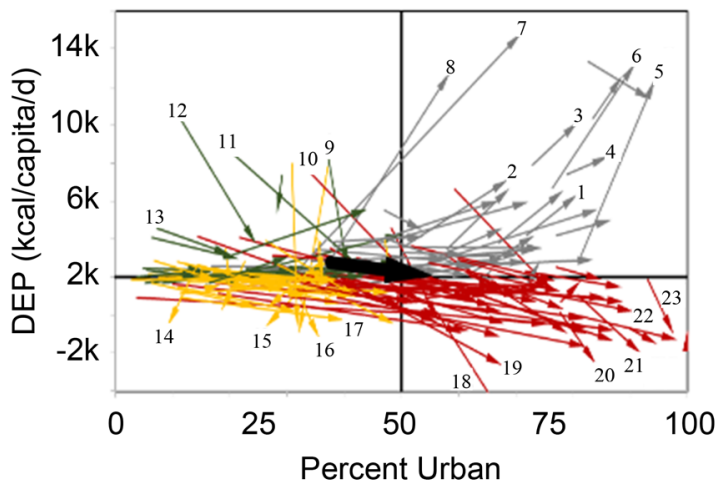

Fig. 3 a 1965; b 2010, Dietary energy production (DEP) versus percent urbanization for 164 countries. Size of data markers proportional to population density. The four quadrants are defined as follows: (I) Gray is $>50 \%$ urban and producing $>2 \mathrm{k} \mathrm{kcal} /$ day (urban-producer); (II) Green is $<50 \%$ urban and $>2 \mathrm{k} \mathrm{kcal} /$ day (rural-producer); (III) Yellow is $<50 \%$ urban and $<2 \mathrm{k} \mathrm{kcal} /$ day (rural-consumer); (IV) Red is $>50 \%$ urban and $<2 \mathrm{k} \mathrm{kcal} /$ day (urban-consumer). c Net trajectories from 1965 to 2010 for 164 countries. Color of arrow indicates quadrant of 2010 data point. Black arrow is starting $(37.5 \%, 2766 \mathrm{kcal} /$ day) and ending $(55.8 \%, 2067 \mathrm{kcal} /$ day) averages of all 164 countries (not shown linear best-fit coefficient of determination of this line when drawn through all 10 averages calculated at all 10 time steps at 5 year increments from 1965 to 2010 is $\mathrm{R}^{2}=0.97$ ). Total net movements over all 45 years between quadrants; IV gains 40 countries, I gains 10 , II loses 44 , and III loses 6 . Some examples are shown (23 of

conditions including climate, soils, net primary production, access to energy, water and technology to subsidize agricultural production, political history, economic policy). However, the collective and remarkably consistent trajectory (Fig. 3c, black arrow, $R^{2}=0.97$ ) downward (three countries every 4 years descended below $2000 \mathrm{kcal} / \mathrm{capita} /$ day) and to the right indicates that an increasing number of large cities and sovereign countries are drawing heavily from the global system and a large fraction of the global population face increasing insecurity for their food supplies while total dietary production continues to increase (Fig. 3d).

Food insecurity is especially pronounced for the increasing numbers of city dwellers, who must import food from rural areas, and of urbanized countries with caloric deficits,

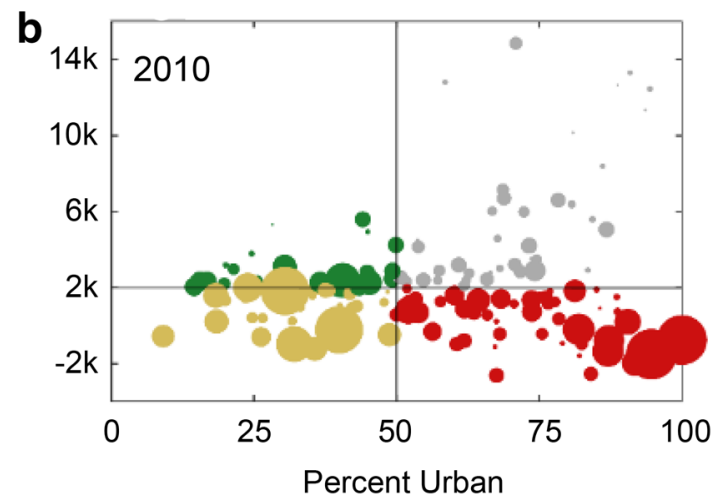

d

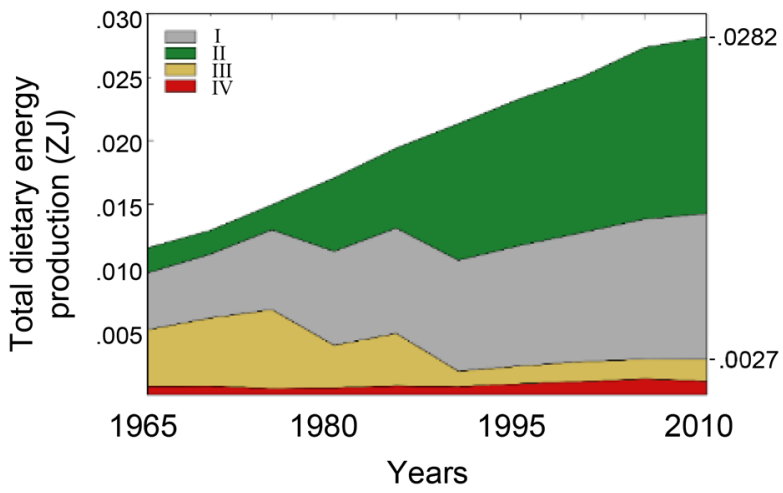

164): (1) United States, (2) Ukraine, (3) Canada, (4) New Zealand, (5) Uruguay, (6) Australia, (7) Malaysia, (8) Paraguay, (9) Mauritius, (10) Fiji, (11) Kiribati, (12) Vanuatu, (13) Solomon Islands, (14) Trinidad and Tobago, (15) Antigua and Barbuda, (16) Grenada, (17) Maldives, (18) Djibouti, [note: final data point for 2010 is $(77,-9666.9)$, but not shown to minimize graph size], (19) Cyprus, (20) United Arab Emirates, (21) Israel, (22) Venezuela, and (23) Belgium. d Global annual total dietary energy produced in zeta joules/year. In 2010, the 66 countries in quads I and II (producers with DEP $>2000 \mathrm{kcal} / \mathrm{capita} /$ day) supplied $0.0254 \mathrm{ZJ}$ or $90.1 \%$ of total DEP $(0.0282 \mathrm{ZJ})$ of caloric energy produced in the world. The remaining ninety-eight countries in quads III and IV (consumers with $\mathrm{DEP}<2000 \mathrm{kcal} /$ capita/day) together supplied remaining $9.7 \%$ or $0.0027 \mathrm{ZJ}$ (Color figure online)

which must import from the decreasing number of countries where food production still exceeds domestic consumption. The steadily increasing urban dilemma is exacerbated by the additional energetic and material costs for the preservation, storage, and transport of food over the steadily increasing distances from source to consumer. Biophysical constraints dictate that cities will never be able to feed themselves. There is simply not enough sunlight and land to grow enough plants for urban agriculture to produce the $2000 \mathrm{kcal} /$ capita/day of photosynthetically derived calories to satisfy the food requirements of urban populations. For example, Singapore requires a minimum of $4.1 \times 10^{12} \mathrm{kcal} / \mathrm{year}$ to feed its population of 5.6 million. If Singapore were to grow highly productive green revolution rice on $100 \%$ of its land area, 


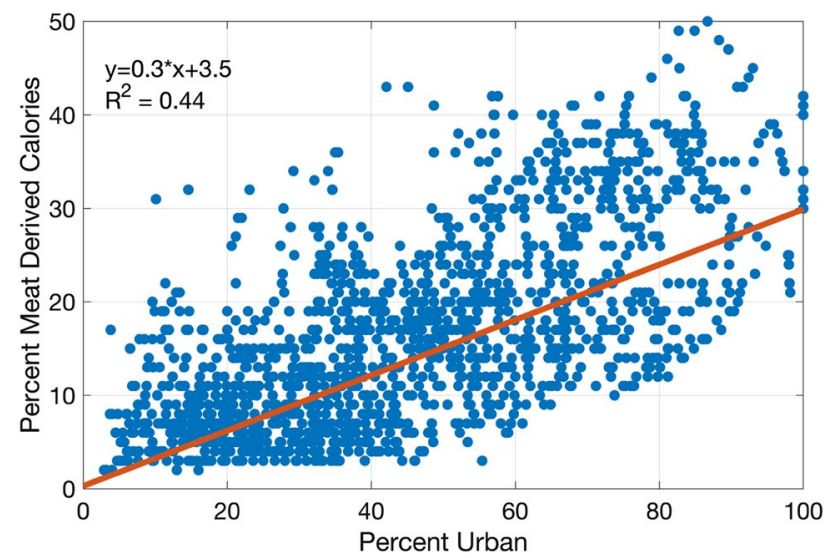

Fig. 4 Percent calories derived from animals in per capita dietary energy supply (DES) as a function of a country's urbanization, $n=1476$ (Color figure online)

the maximum yield would be $0.46 \times 10^{12} \mathrm{kcal} / \mathrm{year}$. So even this unrealistic scenario for urban agriculture would meet only $11 \%$ of the population's caloric needs (Richardson and Moskal 2016; Kim et al. 2015; Peters et al. 2008).

The urban food supply dilemma is exacerbated by a predictable shift toward increased consumption of animal calories, which have higher natural resource demands than vegetable diets. Averaged dietary percent of animal calories increases with urbanization roughly on a rising gradient from $7 \%$ in very rural countries $(<10 \%$ urban) to $32 \%$ in very urban countries ( $>90 \%$ urban) (Fig. 4). These animal calories extol an 11-fold increase (Pimentel and Pimentel 2003) in energy investments (primarily fossil fuels) over plant-based calories and require $36 \%$ of the calories produced by the world's crops for animal feed (Cassidy et al. 2013). Then these animal's metabolic processes lose $88 \%$ of this plant feedstock to respiration producing only $\sim 12 \%$ in edible animal calories (Berners-Lee 2018). At most $4 \%$ of the original $36 \%$ of global feedstock cropping calories $(0.12 \times 0.36=0.04)$ is making it to the table. An energetically inefficient system is growing a meat habit together with a country's degree of urban lifestyle.

\section{Discussion}

The global human population and economy has continued to grow uninterrupted. Continuing growth including DEP is enabled by extraordinary quantities of other forms of energy to power non-metabolic food system processes. The exponential growth in primary energy consumption (Fig. 5) illustrates the precariousness of the domestic and inter-country food self-sufficiency risk depicted in Fig. 1 (Holdren 1991). A large fraction, 15-30\%, of all primary energy consumed by individual nations and the global economy is consumed

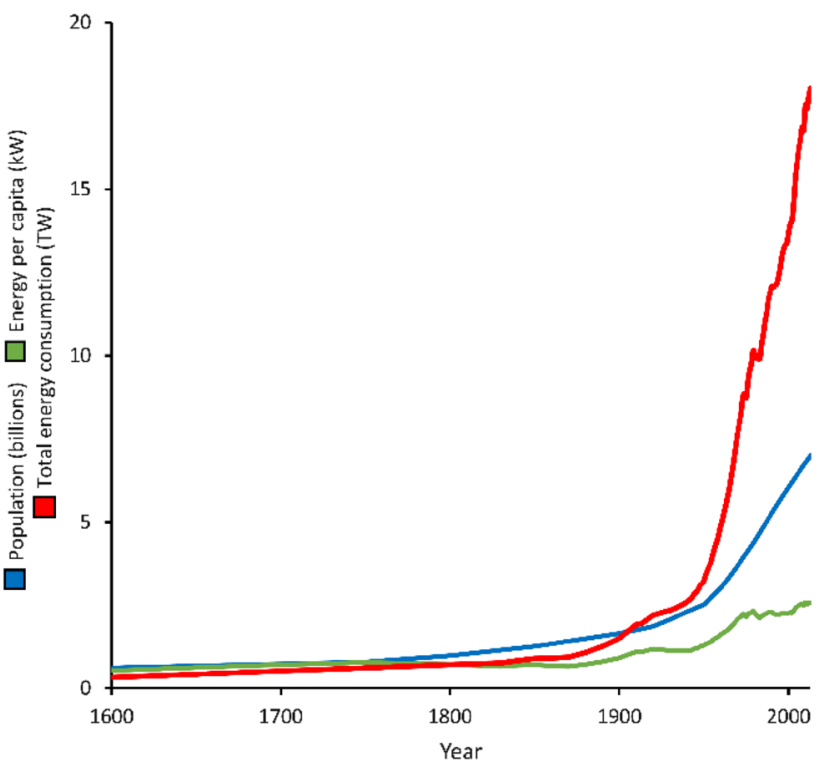

Fig. 5 Global primary power consumption, population, and per capita power consumption. Global energy consumption has remained $\sim 85 \%$ fossil fuels for the last three decades. Global food systems are responsible for $15-30 \%$ of all energy expended (Color figure online)

for the food system - to produce and deliver food from field or ocean to table (Pimentel and Pimentel 2003; Canning et al. 2010; FAO 2011). This primary energy, almost entirely from non-renewable fossil fuels, is expended for fertilizers, machinery, irrigation, herbicides, and insecticides to obtain high yields and for preservation, transportation, distribution, and marketing.

At a global scale, the greater socioeconomic system is efficient at promoting and then distributing food, albeit at astonishing energetic costs. In $2005,52 \%$ of countries produced insufficient per capita calories yet $80 \%$ of all countries were quantified as importing at least $500 \mathrm{kcal} / \mathrm{capita} /$ day (Porkka et al. 2013). Consider that energy consumption for global transportation continues to grow at $1.4 \%$ per yr, now accounts for $25 \%$ of civilization's energy consumed, and remains 95\% dependent on fossil fuels (EIA 2016). The increasing disparity underway between calorie producer and consumer countries (Fig. 1a) is currently enabled by and conditional on this commensurately growing transportation energy investment. Expanding ever-increasing food production, preservation, and distribution between increasingly distal producer and consumer countries requires yet additional energy flows to those extraordinary dispatches depicted in Fig. 5 (Pimentel and Pimentel 2008; Brown et al. 2011). The food system's excessive fossil fuel energy subsidy is unsustainable and represents an Achilles' heel for the sustenance of global human metabolism.

Terrestrial agriculture has been able to keep pace with increasing demand by converting native ecosystems to 
agroecosystems and by using mechanization and technological innovations enabled by fossil fuels to increase yields. For the most part, however, these methods cannot be used in the oceans, where natural biophysical constraints limit the potential to increase primary production and protein supply rates. Marine harvest rates are still increasing while $31 \%$ of marine fish stocks are classified as over-exploited or depleted and another $58 \%$ of fish stocks are fully exploited (FAO 2016). Illegal or unregulated fishing with unknown harvests is significant (World Wildlife Foundation 2015). The impacts of human exploitation on biomass stocks and marine food webs initiate a positive feedback resulting in steadily decreasing biomass. Consequently, as countries continue to fall behind in DEP, they are relying on overharvested marine systems for their own needs with oceans and their marine fisheries currently supplying $17 \%$ of essential protein on a global basis (FAO 2016). Similar to terrestrial systems, unsustainable quantities of energy, mostly from fossil fuels, are needed to further increase marine harvest rates from remaining stocks.

Despite these immediate-term concerns, long-term food security is particularly tied to the success of environmentalism whose goal is to enact consequential methods or change to insure long-term biosphere stability. Our results provide a meaningful way for proposed environmental reforms, practices, and partnerships to be evaluated for their outcomes at varying scales. Despite ongoing improvements, concern for the complexity of agricultural life cycle analyses (LCAs) is genuine given the multitude of continuously changing localto global-scale variables (e.g., natural resources, suppliers, economic conditions, production rates, demography, and on biophysical factors, such as water availability, weather, and soils) (Caffrey and Veal 2013; Sachs et al. 2010; Knapp and van der Heijden 2018; Renouf et al. 2018). Undertaking these analyses is time consuming, expensive, involves extensive or proprietary data, requires higher education training, and altogether faces a mindboggling quantity of food to table systems waiting to be analyzed (Pimentel and Pimentel 2008; Perryman and Schramski 2015). The speed of the global marketplace (Figs. 2, 4) renders completed models of various activities to a commensurately short shelf life. Nevertheless, ongoing refinements and new technologies like vertical farming, underground farming, and artificial meat need these multi-scaled assessments to evaluate impacts versus benefits. These issues are outside the bounds of the present analysis but our model and results provide a quantifiable context for initiating and informing discussions on goals, usefulness, practicality, and overall ability for authorities to enact change while simultaneously forestalling the trends we identify.

\section{Conclusions and Recommendations}

Food security analysis is usually a measure of food available or food consumed by the individual, which involves a higher resolution of analysis of trade and distribution with subsequently nuanced findings based on geographical location and socioeconomic status among others (WHO and FIUWA 2017). For example, Porkka et al. conclude from the same data used herein (although they terminate their findings 2005, our analysis extends to 2010) show that food availability has increased substantially by focusing on dietary energy supply (DES, per capita food supply to the individual, thus accounting for trade and distribution). They also show a slightly different definition of food self-sufficiency (actual quantity of individuals within countries with DEP $>2500 \mathrm{kcal} /$ day) that has remained relatively constant during this time span (Porkka et al. 2013). However, we show that over the last four decades, the number of countries whose borders we contend are a self-organizing and powerful source of political, economic, and environmental control, are no longer supplying sufficient calories to the global market to offset for their own population loading on the same Earth system. That is, while the populations within the remaining calorie positive countries are large which has kept the global average individual DEP high, the average DEP production of the countries that represent these populations is declining (Fig. 1). Further, the decrease is steady, seemingly predictable, and apparently non-reversible (Fig. 3c). This suggests an underlying potential erosion in global food security that has not previously been noted.

We can be a bit more quantitative with our findings. In 2010, the 98 caloric deficit consumer countries in III and IV provided only $0.003 \mathrm{ZJ} /$ year or $9.7 \%$ of the total global caloric energy flow (Fig. 3d), leaving them uniquely dependent on global trade and vulnerable to future environmental or social disruptions. A steadily growing but currently more than one-quarter of the world's population live in III and IV and depend on other countries to produce and supply enough food to make up for within-country DEP deficits. And this current unbalanced global production system requires the extraordinary fossil fuel flows shown in Fig. 5. The food self-sufficiency risk is predictably highest in urbanized-consumer countries (quadrant IV). These are both the least productive, producing a combined total $0.001 \mathrm{ZJ} /$ year over the last 45 years (Fig. 3d) and yet the fastest growing, increasing more than threefold, from 17 to 58 countries, in the same period. As countries shift toward IV, they increase consumption of inefficient animal calories (Fig. 4). The remarkably rapid average trend toward quadrant IV (Fig. 3c) is theoretically predicted for a thermodynamically overburdened and overharvested finite system of countries but also represents strong empirical evidence, as these trends have been 
consistently underway for decades. Unfortunately, our theory and empirical evidence confirms that once countries enter IV, they have almost no chance of recovering. This secures their status as global consumers but more ominously permanently increases the future demands on the shrinking global producers in I and II which altogether further beholden the entire system to yet additional and questionable exogenous energies increases (Fig. 5).

In the short term, scientists, policymakers, politicians, and lay people can use our global and domestic scale results to inform their ongoing assessments of food security risks (Fig. 1). Additional DEP systems research at multiple scales (e.g., continents, biomes, economic status, arable lands) will inform the stability or precariousness of each trajectory and help countries assess their food vulnerabilities (Fig. 3). As of yet, untested technologies at scale like genetic decreases in respiration to increase yields or purported high-yield agroecological farming techniques need heightened awareness and ground truthing (South et al. 2019; Schutter 2011). At one extreme are countries that have high food self-sufficiency with large areas of arable land, productive agriculture, and relatively rural low-density populations that currently produce sizeable food surpluses. Domestic food production levels may be of only a small concern and international sales can be carefully encouraged for benefits in return. At the other extreme, are small, highly urbanized countries that are extremely vulnerable to socio-political upheaval and environmental catastrophe due to limited arable land and net food deficits. Diet choices, magnitudes of domestic food production, and availability and viability of international supplies also have a heightened sense of urgency in these cases. All countries would benefit by reducing animal diets ensuing both less fossil fuel consumption and the return to the market place of a large proportion of the edible calories produced by the world's crops currently being used for animal feed (i.e., $~ 36 \%$ ). Presumably, a portion of the land currently dedicated to animal calorie production could also be transitioned back to crop production. DEP magnitudes depicted in Fig. 3 and domestic food securities would improve. Meanwhile, agriculture's role in climate change, which is significantly beyond the scope of work herein, cannot be ignored. Agriculture is a looming constraint on future decisions where greenhouse gases from still expanding transportation, to livestock outgassing, and deforestation are consequential concerns. For example, reduced animal diets and carbon sequestration in harvesting techniques are urgently being promoted (Toensmeier 2016).

At the global scale, the long-term outlook is challenging, in large part because a growing global population and economy will require yet more energy to provide additional global production and trade operations. Despite gains in renewable energy production, the majority of the extrametabolic energy is still obtained from fossil fuels and the finite reserves of oil, gas, and coal are being rapidly depleted. War, social discord, climate change, increasing pollution, and biomass depletion all contribute, albeit in ways that are difficult to quantify and predict, to increasing risks to maintaining adequate food supplies. We contend that as natural resources wane, country-level boundaries and policies and the self-organizing powers attributed to their politics, economics, social norms, and military will always maintain a consequential and non-trivial degree of importance on food production, storage, and import and export decisions. Currently, the trend toward increased urbanization and heavier animal calorie diets, fewer large food-producing regions, and an expansive food preservation and global delivery system wholly dependent on fossil fuels, suggests global food self-sufficiency is declining and becoming less stable and resilient to external pressures.

\section{Materials and Methods}

Figure 1: United Nations data for populations (Nations 2014) and Porkka et al.'s data for dietary energy produced (DEP) (Porkka et al. 2013) are used where DEP is the per capita grown or captured caloric energy, including both animal and crop calorie production, available for consumption. One inherent strength in Porkka et al.'s methods is that crop calories routed to feedstock are not counted until they become animal calories (i.e., no double counting). These feedstock calories are temporarily lost but later returned as a less calorie containing animal product. A significant portion of feedstock calories are lost as waste heat in the metabolic processes (i.e., $>80 \%$ ) which then lowers DEP as animal calorie production increases. Porkka et al. note that extreme cases of high animal consumption and inefficient diets result in cases of negative DEP. Final data used are compiled in Source Data. Worksheet titled country data includes raw DEP data by country and year. Worksheets DEP statistics and Quadrant statistics are the resultant calculations for Fig. 1a, b, respectively.

Average [red line] :

$$
\text { Average DEP }=\frac{\sum \text { DEP of each country }}{164 \text { countries }}
$$

Standard deviation [blue line] :

$$
\text { Stddev of DEP }=\left(\frac{\sum(\text { DEP average }- \text { country DEP })^{2}}{164 \text { countries }}\right)^{1 / 2}
$$

Global average [green line] :

$$
\text { Global DEP }=\frac{\sum(\text { country DEP } \times \text { population })}{\sum \text { country population }}
$$


Porkka et al's dataset for DEP spanned 40 years from 1965 to 2005 in 5-year averaged increments; thus 9 data points total for each country (i.e., 1965, 1970, and so on). We then used similar methods as expressed in their supplementary information including clarifying personal emails with Dr. Porkka to calculate DEP for 2010 which is included in the Source Data. Thus Fig. 1a includes ten timesteps from 1965 to 2010 at 5-year increments.

Figure 3: United Nations data for percent urbanization (United Nations 2014) and population density (World Populations Prospects 2017), and Porkka et al.'s data for dietary energy produced (DEP) (Porkka et al. 2013) are used in Fig. 3a-c. Final data used are compiled in Source Data worksheet titled country data that includes DEP, per capita population density, and $\%$ urban data by country and year. In Fig. 3d, for each 5-year time step starting with 1965 through 2010 (10 steps), for each country, we calculate total dietary energy produced by multiplying population by DEP (both values located in worksheet titled country data) and add the totals for each of the four quadrants. An example calculation for 2010 is provided in Source Data worksheet titled 2010 quad totals.

Singapore's food needs: The population and land mass of Singapore in 2016 were $\sim 5.6 \times 10^{6}$ and $717 \mathrm{~km}^{2}$ (World Bank retrieved 11-13-17). Assuming a $2000 \mathrm{kcal} /$ day diet, Singapore's inhabitant's require $\left(5.6 \times 10^{6}\right.$ people $) \times(2000 \mathrm{kcal} /$ person/day $) \times(365$ day $/$ year) $=4.1 \times 10^{12} \mathrm{kcal} /$ year. Assume rice produces 5 tonnes/ha/year which is above the global average of $4.6 \mathrm{t} / \mathrm{ha} / \mathrm{year}$ in 2016 and also assume rice $=1290 \mathrm{kcal} /$ $\mathrm{kg}$. Total rice energy production of Singapore $=(5$ tonnes/ha $) \times\left(717 \mathrm{~km}^{2}\right) \times\left(100 \mathrm{ha} / \mathrm{km}^{2}\right) \times(1000 \mathrm{~kg} /$ tonne $) \times(1290 \mathrm{kcal} / \mathrm{kg})=0.46 \times 10^{12} \mathrm{kcal} /$ year. The percent of diet is then $\left(0.46 \times 10^{12} \mathrm{kcal} / \mathrm{year}\right) /\left(4.1 \times 10^{12} \mathrm{kcal} /\right.$ year) $=11 \%$.

Figure 4: Percent calories in dietary energy supply (DES) from animals are from Porkka et al. (2013). These are per capita calories supplied to the individuals of each country. Percent urbanization is from the United Nations (United Nations 2014). Original data from Porkka et al. and the UN report are available in Source Data, worksheet titled country data. These data are reordered for Fig. 4 in worksheet titled animal calories and urbanization. This represents 164 countries over nine time steps at 5 year intervals for a total of $n=1476$ data points. Using the reordered data in the worksheet titled animal calories and urbanization, we first captured all data points at less than $10 \%$ urbanization $(n=57)$ to calculate $7 \%$ from animal calories. Similarly, we captured all data points greater than $90 \%$ urbanization $(n=39)$ to obtain $32 \%$ from animal calories. Examples of these calculations are available in Source Data.
Figure 5: Similar to Ehrlich et al. with updated data (2012). Primary energy consumption is derived from Smil (2010), the EIA (2013), and BP (2017) and population is UN data (1999). Final data used are compiled in Source Data, worksheet titled global energy consumption.

Acknowledgements We are grateful for Dr. Miina Porkka and colleagues' published data and Dr. Porkka's helpful guidance with these data.

Author Contributions JRS, CBW, GS, DM, and JHB all contributed to the conception, design, and results of the model. JRS, CBW, and JHB wrote and revised the manuscript.

\section{Compliance with Ethical Standards}

Conflict of interest On behalf of all authors, the corresponding author states that there is no conflict of interest.

Data Availability Authors confirm that all data are available in the main text or the supplementary information.

Open Access This article is distributed under the terms of the Creative Commons Attribution 4.0 International License (http://creativeco mmons.org/licenses/by/4.0/), which permits unrestricted use, distribution, and reproduction in any medium, provided you give appropriate credit to the original author(s) and the source, provide a link to the Creative Commons license, and indicate if changes were made.

\section{References}

Alexandratos N, Bruinsma J (2012) World agriculture towards 2030/2050: the 2012 revision. FAO, Rome

Berners-Lee M, et al (2018) Current global food production is sufficient to meet human nutritional needs in 2050 provided there is radical societal adaptation. Elem Sci Anthr 6(1)

Bettencourt LM et al (2007) Growth, innovation, scaling, and the pace of life in cities. Science 104(17):7301-7306

BP (2017) Statistical review of world energy. https://www.bp.com/ content/dam/bp/en/corporate/pdf/energy-economics/statistica 1-review-2017/bp-statistical-review-of-world-energy-2017-fullreport.pdf. Accessed 13 Nov 2017

Briggs D (1999) Environmental health indicators: framework and methdologies. World Health Organization, Geneva

Brown JH et al (2011) Energetic limits to economic growth. Bioscience 61(1):19-26

Brown JH et al (2013) Macroecology meets macroeconomics: resource scarcity and global sustainablity. Ecol Eng 65:24-32

Burger JG (2015) Macroecology and sociobiology of humans and other mammals, in biology. University of New Mexico, Albuquerque

Burger J, Weinberger V, Marquet P (2017) Extra-metabolic energy use and the rise in human hyper-density. Nat Sci Rep 7:43869

Caffrey KR, Veal MW (2013) Conducting an agricultural life cycle assessment: challenges and perspectives. Sci World J 2013(472431):1-13

Canning C et al (2010) Energy use in the U.S. Food System. USDA, Washington

Cassidy ES et al (2013) Redefining agricultural yields: from tonnes to people nourished per hectare. Environ Res Lett 8(3):034015 
Chaudhary A, Gustafson D, Mathys A (2018) Multi-indicator sustainability assessment of global food systems. Nat Commun 9(1):848

Clements FE (1916) Plant succession: an analysis of the development of vegetation. Carnegie Instittion of Washington, Washington, DC

Cole MB et al (2018) The science of food security. Nature. https://doi. org/10.1038/s41538-018-0021-9

Cumming GS et al (2014) Implications of agricultural transitions and urbanization for ecosystem services. Nature 515:50

Duh $\mathrm{J}$ et al (2008) Rates of urbanisation and the resiliency of air and water quality. Sci Total Environ 400(1-3):238-256

Ehrlich PR, Harte J (2015) Food security requires a new revolution. Int J Environ Stud 72(6):908-920

Ehrlich PT, Kareiva PM, Daily GC (2012) Securing natural capital and expanding equity to rescale civilization. Nature 486(7401):68-73

EIA (2013) http://www.eia.gov/cfapps/ipdbproject/iedindex3. $\mathrm{cfm} ? \mathrm{tid}=5 \& \mathrm{pid}=53 \&$ aid $=1 \&$ cid $=$ regions\&syid $=1994 \&$ eyid $=2$ 013\&unit=TBPD. Accessed 1 Mar 2019

EIA (2016) International energy outlook. EIA, pp 1-290

FAO (2009) High Level Expert Forum - how to feed the world in 2050. Office of the Director, Agricultural Development Economics Division, Rome

FAO (2011) Energy smart food for people and climate. Food and Agriculture Organization of the United Nations, Rome

FAO (2016) The state of food and agriculture: climate change, agriculture food and security. Rome

Godfray HCJ et al (2010) Food security: the challenge of feeding 9 billion people. Science 327:812-818

Hall CAS, Day JW (2009) Revisiting the limits to growth after peak oil. Am Sci 97(3):230-237

Holdren JP (1991) Population and the energy problem. Popul Environ 12(3):231-255

Kim K, Burnett K, Ghimire J (2015) Assessing the potential for food and energy self-sufficiency on the island of Kauai, Hawaii. Food Policy 54:44-51

Knapp S, van der Heijden MGA (2018) A global meta-analysis of yield stability in organic and conservation agriculture. Nat Commun 9(1):3632

Nations, U. (2014) World urbanization prospects, P.D.T.R. Department of Economic and Social Affairs, (ST/ESA/SER.A/366)

Nekola JC et al (2013) The Malthusian-Darwinian dynamic and the trajectory of civilization. Trends Ecol Evol 28(3):127-130

Odum EP (1969) The strategy of ecosystem development. Science 164(3877):262-270

Pascual U, Barbier E (2006) Deprived land-use intensification in shifting cultivation; the populatin pressure hypothesis revisted. Agric Econ 34:155-165

Perryman ME, Schramski JR (2015) Evaluating the relationship between natural resource management and agriculture using embodied energy and eco-exergy analyses: a comparative study of nine countries. Ecol Complex 22:152-161

Peters CJ et al (2008) Mapping potential foodsheds in New York State: a spatial model for evaluating the capacity to localize food production. Renew Agric Food Syst 24:72-82

Pimentel D, Pimentel M (2003) Sustainability of meat-based and plantbased diets and the environment. Am J Clin Nutr 78(3):660S-663S

Pimentel D, Pimentel M (2008) Food, energy, and society. CRC Press, Boca Raton

Porkka M et al (2013) From Food Insufficiency towards trade dependency: a historical analysis of global food availability. PLoS ONE $8(12): 1-12$
Prigogine I (1977) Time, structure, and fluctuations. In Nobel Lecture. Universite Libre de Bruxelles, Brussels, Belgium and the University of Texas at Austin, Austin, Texas, USA

Rees WE (1999) Consuming the earth: the biophysics of sustainability. Ecol Econ 29(1):23-27

Rees WE (2012) Cities as dissipative structures: global change and the vulnerability of urban civilization, in sustainability science: the emerging paradigm and the urban environment. Springer, New York, pp 247-273

Renouf MA et al (2018) Effectiveness criteria for customised agricultural life cycle assessment tools. J Clean Prod 179:246-254

Richardson JJ, Moskal LM (2016) Urban food crop production capacity and competition with urban forest. Urban For Urban Green 15:58-62

Sachs J et al (2010) Monitoring the world's agriculture. Nature 466:558

Schramski JR, Gattie DK, Brown JH (2015) Human domination of the biosphere: rapid discharge of the earth-space battery foretells the future of humankind. Proc Natl Acad Sci 112(31):9511-9517

Schutter OD (2011) Agroecology and the right to food. H.R. Council, United Nations

Smil V (2010) Energy transitions: history, requirements, prospects. Praeger, Santa Barbara

Smil V (2013) Harvesting the biosphere: what we have taken from nature. MIT Press, Cambridge

South PF et al (2019) Synthetic glycolate metabolism pathways to stimulate crop growth and productivity in the field. Science 363(6422):45-48

Tilman D et al (2011) Global food demand and the sustainable intensification of agriculture. Proc Natl Acad Sci 108(50):20260-202264

Toensmeier E (2016) The carbon farming solution: a global toolkit of perennial crops and regenerative agriculture practices for climate change mitigation and food security. Chelsea Green Publishing, White River Junction

United Nations, Department of Economic and Social Affairs, Population Division (2014) World Urbanization Prospects: The 2014 Revision, (ST/ESA/SER.A/366)

United Nations Population Division (1999) The world at six billion. United Nations Population Division

Waters CN et al (2016) The Anthropocene is functionally and stratigraphically distinct from the Holocene. Science 351(6269):aad2622

WFP, FIA (2015) The state of food Insecurity in the world 2015, meeting the 2015 international hunger targets, taking stock of uneven progress. FAO, Rome

WHO, FIUWA (2017) The state of food security and nutrition in the world 2017. Building resilience for peace and food security. FAO, Rome

World Populations Prospects 2017-Data Pooklet (ST/ESA/ SER.A/377). https://esa.un.org/unpd/wpp/Download/Standard/ Population/. Accessed 12 June 2017

World Wildlife Foundation (2015) Illegal fishing; which fish species are at the highest risk from illegal and unreported fishing. World Wildlife Foundation, Gland

Publisher's Note Springer Nature remains neutral with regard to jurisdictional claims in published maps and institutional affiliations. 